\title{
Avaliação automática da taxa de crescimento de colônias de leveduras incubadas em placas de Petri usando Plataforma Móvel
}

\section{Automatic Evaluation of Colonies Growth rate of Yeasts incubated in Petri dishes using Mobile Platform}

\author{
Alecsander Pereira Martins ${ }^{1}$; José Carlos Pizolato Junior²; Valdinei Luís Belini ${ }^{3}$
}

\section{Resumo}

O presente trabalho propõe um método automático baseado em visão computacional implementado em plataforma móvel capaz de monitorar o crescimento de colônias de leveduras Sacchromyces cerevisiae incubadas em placas de Petri. O algoritmo otimizado para o processamento de imagem desempenha esta tarefa sem intervenção humana a partir de imagens de colônias de microrganismos em diferentes fases de evolução. A contribuição desse artigo é o desenvolvimento de uma ferramenta móvel de resposta rápida para auxiliar especialistas em bioprocessos no monitoramento do crescimento de colônias sem o uso da convencional e imprecisa técnica manual. Os resultados obtidos demonstram, com sucesso, alterações dimensionais em colônias em uma maneira mais rápida e exata quando comparado com o método convencional, com a vantagem adicional da versatilidade em produzir resultados mais exatos e consistentes com maior significância estatística.

Palavras-chave: Processamento de Imagem. Levedura. Visão Computacional. Plataforma móvel.

\begin{abstract}
This paper proposes an automatic method based on computer vision implemented in mobile platform capable of monitoring the growth of microbial colonies incubated in Petri dishes. The developed optimized image processing algorithm performs this task without human intervention from images of colonies of the microorganism in different evolution phases. The contribution of this paper is the development of a fast and robust mobile tool to assist bioprocess experts in monitoring the growth of colonies without using the conventional error prone evaluation techniques. The obtained results successfully demonstrated dimensional alterations in colonies in a faster and more precise fashion when compared with the conventional method, with the additional advantage of versatility in producing reliable estimation of the growth rates with higher statistical significance.
\end{abstract}

Keywords: Image Processing. Yeast. Computer Vision. Mobile Platform.

\footnotetext{
${ }^{1}$ Mestre em Engenharia Elétrica, Universidade Estadual de Londrina; apms6592@gmail.com

${ }^{2}$ Departamento de Engenharia Elétrica, Universidade Federal de São Carlos-UFSCar; jcpizolato@yahoo.com.br

${ }^{3}$ Departamento de Engenharia Elétrica, Universidade Federal de São Carlos-UFSCar; belini@ufscar.br
} 


\section{Introdução}

Com o aumento da presença da biotecnologia na produção alimentícia e principalmente de bioenergia (SASANO et al., 2012), os processos fermentativos têm ocupado cada vez mais destaque e importância no desenvolvimento de recursos e de pesquisas no segmento de bioprocessos. Para as experiências de laboratório em biotecnologia são utilizados recipientes circulares e transparentes conhecidos como placas de Petri. Essas placas acondicionam e permitem acompanhar o desenvolvimento de microrganismos que crescem num meio sólido denominado ágar. Esse meio oferece condições ideais para o desenvolvimento de microrganismos de maneira consistente e estável num ambiente em estufa com temperaturas controlada. $\mathrm{Na}$ cultura realizada em placas de Petri, as condições favoráveis ao desenvolvimento dos microrganismos possibilitam que amostras de leveduras ou bactérias promovam o surgimento e o crescimento de unidades formadoras de colônias (UFC) que são visíveis ao olho humano. Nesse contexto, o estudo da taxa de crescimento de colônias de microrganismos pode fornecer informações primordiais para avaliar os efeitos dos seguintes agentes: antibióticos, inibidores de crescimento, radiação, temperatura, pH, composição do meio de cultura, drogas, nutrientes, estresse fisiológico, entre outros fatores ambientais (LAWLESS et al., 2010). No contexto funcional genômica, a levedura Saccharomyces cerevisiae tem emergido como o organismo modelo para estudos de células (MEMARIAN et al., 2007), sequenciamento de genoma (GOFFEAU et al., 1996), (GHAEMMAGHAMI et al., 2003), (Krogan et al., 2006). Desta forma, este mesmo organismo será utilizado nas avaliações experimentais neste trabalho.

Tradicionalmente, a verificação dimensional de colônias utiliza uma análise visual a partir de medições (posicionamento do instrumento, leitura e interpretação da escala) realizadas com uma régua ou paquímetro. Grandes diferenças qualitativas em crescimento podem ser facilmente observadas a olho nu, mas medidas quantitativas de crescimento são necessárias para detectar pequenas diferenças de crescimento das colônias (ADDINALl et al., 2008). Embora esta técnica seja muito conhecida e de baixo custo, o tempo demandado nas medições convencionais e as imprecisões nos resultados tem motivado a pesquisa por métodos automáticos. Esta tarefa de observação direta muito minuciosa e exaustiva e depende da experiência do especialista. Neste caso, fatores como cansaço, fadiga e distrações do especialista podem contribuir ao registro de tamanhos de colônias diferentes das dimensões verdadeiras. Além disso, o tempo necessário na medição convencional é um fator limitante quando existe a demanda de diversos acompanhamentos simultâneos de crescimento de colônias em outras placas de Petri.

Com o propósito de minimizar a influência do fator humano e produzir resultados mais exatos e consistentes, muitas propostas têm automatizado a contagem e a avaliação da taxa de crescimento de colônias em meio sólido (placas de Petri). No entanto, a maioria dos trabalhos aplicou rotinas padrões de processamento de imagens em um programa computacional Applesoft Basic (Costello; MONK, 1985) sobre imagens obtidas por um microscópio. A varredura de todos os pixels da imagem é obtida num algoritmo que distingue limiares nos pixels de acordo com ajuste manual de luminosidade. (BISTON et al., 2003). Neste algoritmo as imagens de placa de Petri contendo colônias de leveduras foram analisadas através da aplicação de filtros espaciais de erosão e dilatação. Outra alternativa ao processo convencional de inspeção dimensional do crescimento de colônias foi também proposta por (MEMARIAN et al., 2007). Este sistema de visão computacional apresenta restrições de uso devido à necessidade de um software não comumente disponível em laboratórios de biotecnologia, o software Matlab. Além disso, a identificação de crescimento de colônias era realizada em recipientes retangulares com marcações especiais. Na identificação da densidade de colônias de Saccharomyces cerevisiae no trabalho de (LAWLESS et al., 2010) ocorre a localização de microrganismos 
cultivados em ágar sólido, verificando o crescimento do conjunto de colônias dispostas no formato retangular. No trabalho publicado por (LI; WADso, 2011), o software Matlab também foi utilizado para analisar o comportamento de crescimento de colônias medindo a produção de calor do microrganismo durante seu desenvolvimento. O algoritmo de Watershed (ROBINson et al., 1998) é aplicado para a determinação do número de células e detecção de borda morfológica para a avaliação do tamanho da colônia. $\mathrm{Na}$ análise de imagens de leveduras aplicando algoritmo de Hough (YAmAshitA et al., 1993) uma imagem microscópica digitalizada de leveduras é analisada com base na transformação de Hough, e as células circulares são assim detectadas. (ZALEWski; BUCHHOLZ, 1996) monitoraram o crescimento da cultura de $S$. cerevisiae por meio de um programa computacional escrito em linguagem de programação OCCAM 2. O algoritmo detecta variações de formato nas colônias na identificação do crescimento com técnicas de erosão e de dilatação. (BotTigli et al., 2006) combinaram regiões de interesse da imagem com uma técnica baseada em rede neural artificial para contar colônias de células em placas de Petri. (CARPENTER et al., 2006) desenvolveram um código aberto, denominadoCellProfiler, paraidentificaremedir uma variedade de objetos biológicos em imagens por meio de algoritmos de segmentação. Recentemente, a utilização de um classificador baseado em Support Vector Machine detectou e separou aglomerados de colônias para permitir a contagem e a distinção de diferentes espécies de colônias de bactérias (CHEN; ZHANG, 2009). O efeito da autofluorescência também foi explorado em imagens digitais para detectar o surgimento de colônias em meio sólido, gerações que antecedem sua detecção direta pelo olho humano (LONDON et al., 2010).

Apesar da exatidão e da consistência dos resultados demonstrados por essas propostas, o desempenho da maioria dos sistemas automáticos é dependente de uma plataforma fixa composta por uma câmera de vídeo para a aquisição de imagens e um computador pessoal (PC) para executar os algoritmos de análise das imagens. Essa exigência contribui para restringir o uso de tais métodos a laboratórios de pesquisa ou ambientes restritos.

O aumento da capacidade de processamento e de armazenamento de dados, associados à integração de câmeras de vídeo de alta resolução aos modernos telefones celulares de baixo custo, têm permitido ampliar substancialmente o elenco de aplicações desses sofisticados equipamentos portáteis. Nesse sentido, este artigo propõe a automação do monitoramento de colônias de leveduras em placas de Petri a partir da integração de hardware e de software em uma única plataforma. Para tanto, esta proposta usou um aparelho celular Samsung modelo Omnia WSGH-i677UG, 1,4 GHz, 512 MB (RAM) e sistema operacional Windows Phone 7.5.

Com a presente proposta, pretende-se contribuir para a redução da subjetividade do especialista no monitoramento do crescimento de colônias e das incertezas estatísticas, quando comparadas com a técnica manual.

Embora a capacidade de processamento dessas plataformas móveis tenha aumentado vários algoritmos de processamento de imagem originalmente desenvolvidos para PC ainda são computacionalmente onerosos para serem executados em aparelhos celulares. Nesse contexto, a otimização de um algoritmo de processamento de imagem para PC, de tal maneira que ele possa ser executado em plataforma móvel, representa outra contribuição deste trabalho.

Diferente dos estágios de processamento digital de imagens tradicionais, os quais demandam maior custo computacional, esse trabalho baseia-se na utilização de técnicas de processamento digital somente no domínio espacial da imagem. Como resultado, o algoritmo implementado trabalha de modo direto a morfologia matemática dos pixels em imagens previamente convertidas para o domínio binário.

O artigo é organizado como segue: a Seção 2 apresenta os procedimentos necessários para a 
medida e a avaliação do crescimento das colônias. O sistema de monitoramento proposto é introduzido na Seção 3. A Seção 4 apresenta o processamento digital da imagem. Os resultados obtidos e discussões estão na Seção 5, e a conclusão na Seção 6.

\section{Procedimento convencional monitoramento de colônias}

Em um procedimento convencional, o monitoramento de colônias instaladas em placa de Petri ocorre pela identificação visual, i.e., a olho nu, de uma ou mais colônias. A verificação do crescimento de colônias é realizada pela medição manual do diâmetro dessas estruturas ao longo de um período de incubação em estufa sob temperatura controlada. Esse tipo de medição é conduzido por um técnico especialista que utiliza a escala graduada de uma régua ou paquímetro (Figura 1). Nesse procedimento há uma incerteza associada à de operação do instrumento pelo técnico (BARAZZETTI; SCAIONI, 2009). Desta forma, o método convencional de medição pode gerar diferentes valores entre técnicos de laboratórios para a mesma região das colônias em uma placa de Petri. Esta inconsistência demanda maior quantidade de repetições nas medições convencionais para produzir resultados mais exatos.

Figura 1. Medição convencional de tamanho de colônia de microrganismos em placa de Petri com uma (a) régua e um (b) paquímetro.

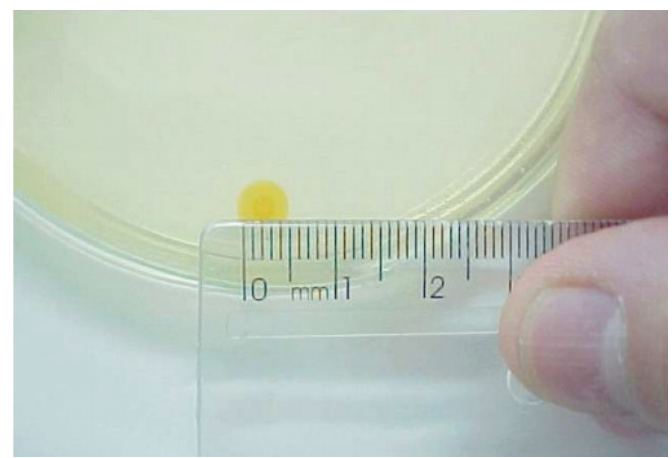

(a)

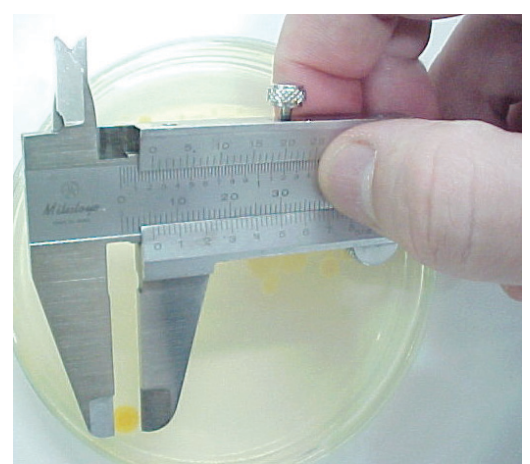

(b)

Fonte: Autor 


\section{Sistema de monitoramento proposto}

O sistema de visão computacional proposto neste trabalho para o monitoramento da evolução espacial de colônias numa placa de Petri é ilustrado na Figura 2.

Figura 2. Diagrama em blocos do método proposto para o monitoramento de colônias instaladas em placa de Petri.

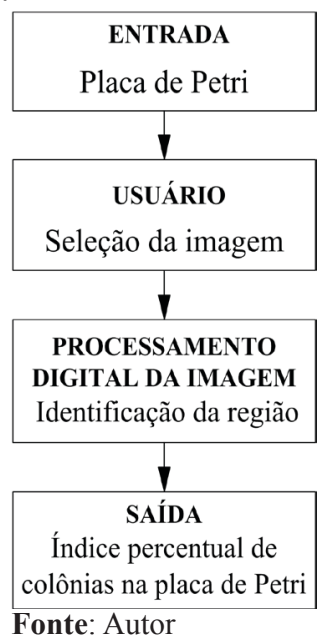

A entrada do sistema corresponde a uma placa de Petri, enquanto a aquisição da imagem é desempenhada por uma câmera fotográfica digital do aparelho celular posicionado sobre a placa. O usuário seleciona a imagem da placa de Petri diretamente na tela do telefone celular. A imagem capturada é processada e analisada digitalmente para a identificação das colônias para, subsequentemente, fornecer dados quantitativos da evolução dos microrganismos. Finalmente, a saída do sistema informa a porcentagem de ocupação das colônias na placa de Petri.

Comparado ao sistema convencional, a metodologia proposta oferece a vantagem de monitoramento da evolução espacial de colônias num tempo menor, com ausência de subjetividade das medições e minimização dos erros de repetibilidade de medição para obter valores com maior exatidão.

Entretanto, na obtenção das imagens, o método proposto é sensível ao deslocamento lateral da placa de Petri. Para eliminar essa influência, este trabalho adotou uma base suporte existente em um procedimento convencional para a contagem manual de colônias (Figura 3). Esta base garante um sistemático posicionamento da placa de Petri pelo correto alinhamento da câmera fotográfica para a obtenção de imagens sucessivas. As características originais dessa base (guia da placa de Petri, retro iluminação constante e lente) foram preservadas.

A distância focal do sistema de aquisição da imagem, ilustrado na Figura 3(b), é determinada pelos $150 \mathrm{~mm}$ de comprimento da base suporte. Ensaios comparativos (dados não mostrados) sob diferentes distâncias focais entre a placa de Petri e a câmera digital indicaram que distâncias inferiores a $115 \mathrm{~mm}$ produzem distorções na imagem, enquanto distâncias focais superiores a $270 \mathrm{~mm}$ resultam na ausência de visualização do início do surgimento de colônias e erros de repetibilidade.

Em uma avaliação manual, um técnico verifica o crescimento das colônias e o seu tempo de incubação, sem considerar uma relação métrica na placa de Petri. Apenas é considerada a diferença de ocupação das colônias nas placas de Petri observadas.

No sistema de aquisição de imagem ilustrado na Figura 3 o conjunto inferior da base suporte é provido de uma lâmpada para a retro iluminação da placa de Petri, mantendo a luminosidade na região inferior controlada. O aquecimento proporcionado por esta iluminação colabora para manter a temperatura da placa de Petri próxima à temperatura da estufa de incubação. No conjunto superior do sistema de aquisição da imagem foi adicionado um tubo de polietileno com aberturas para a câmera fotográfica do celular e a placa de Petri. Este tubo de proteção é fixado ao suporte do aparelho celular para evitar potenciais interferências originadas pela alteração da luz ambiente ou surgimento de sombras ou reflexos durante a etapa de captura da imagem.

$\mathrm{Na}$ necessidade de trocas sucessivas da placa de Petri durante o período de incubação e o correspondente monitoramento, o conjunto superior do sistema de aquisição (aparelho celular e tubo 
de proteção) pode ser removido. No momento de monitorar outra placa de Petri, a mesma deve ser reposicionada sob o conjunto inferior da base suporte. Neste contexto, o usuário posiciona o conjunto superior do sistema de aquisição, alinhando-o com a base suporte e a placa de Petri (no fundo do tubo de proteção), a qual possui dimensões físicas padronizadas.

Figura 3. Sistema de visão proposto com o sistema de aquisição de imagem. (a) Aparelho celular posicionado sobre uma placa de Petri na base suporte com o tubo de proteção da iluminação. (b) Detalhe da distância focal entre a câmera do aparelho celular e a placa de Petri localizada no conjunto inferior do sistema de aquisição da imagem.

Aparelho celular

posicionado sob o suporte do conjunto superior de

Conjunto inferior do aquisição da imagem sistema de aquisição

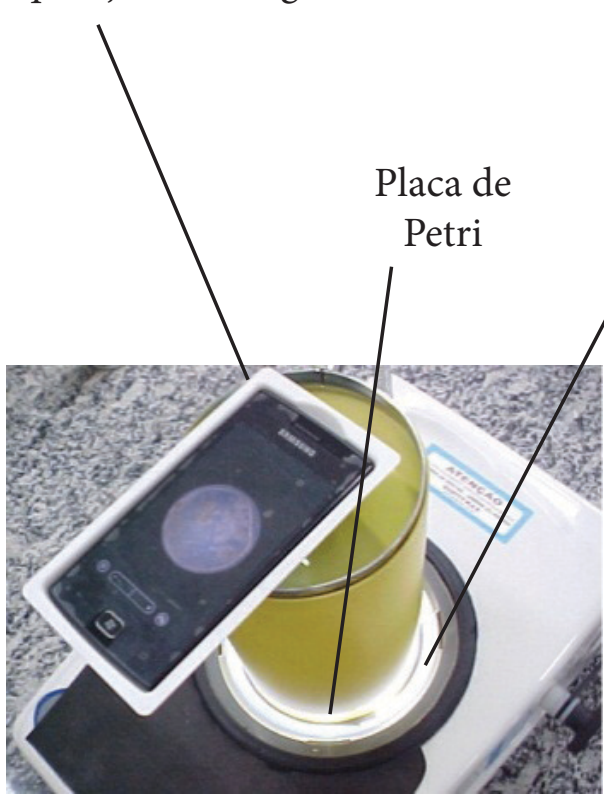
composto pela

Distância focal retro iluminação fixa $(150 \mathrm{~mm})$

(a)

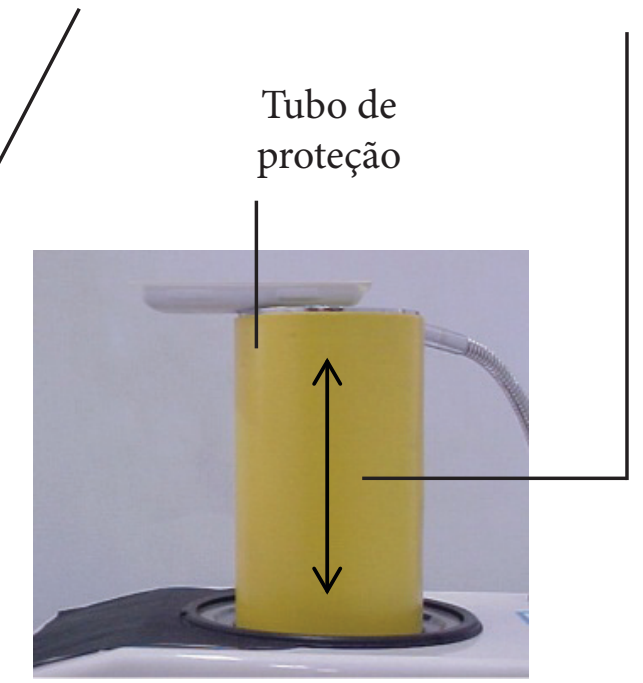

(b)

Fonte: Autor 


\section{Processamento digital da imagem}

O processamento digital é realizado no domínio espacial da imagem e atua diretamente na morfologia dos elementos de imagem (pixels), conforme ilustra a Figura 4.

Figura 4. Diagrama em blocos do processamento digital da imagem no sistema de monitoramento proposto.

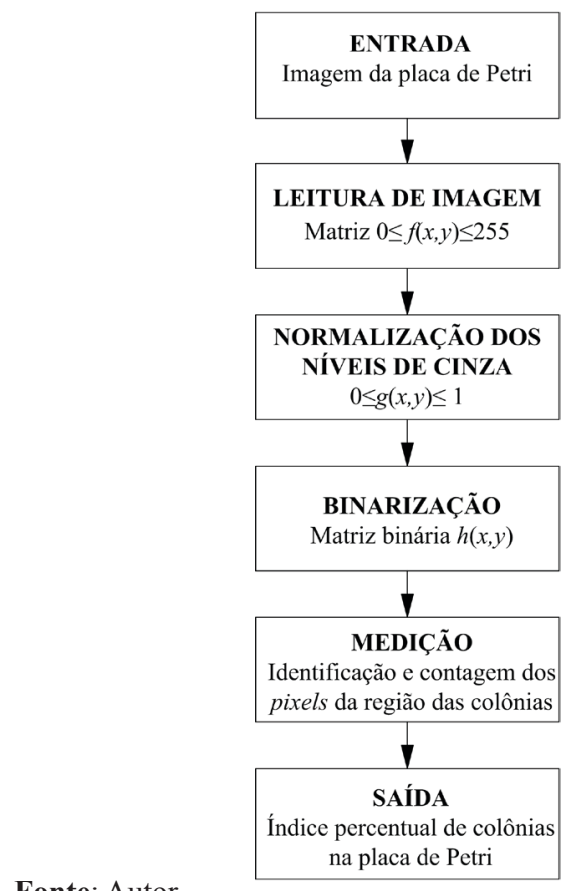

A entrada do processamento de imagem é definida pela imagem real da placa de Petri com diâmetro físico útil de $88 \mathrm{~mm}$. Na sequência, a imagem original em formato JPEG é convertida em uma matriz de níveis de cinza, $f(x, y)$, sendo que $x$ e $y$ representam, respectivamente, as coordenadas da linha e da coluna de cada posição do pixel. O bloco de normalização de níveis de cinza transforma estes valores, originalmente compreendidos entre 0 e 255, para um intervalo entre 0 e 1 .

$$
g(x, y)=\frac{f(x, y)}{\max (f(x, y))}
$$

sendo: $f(x, y): \quad$ o valor da intensidade original $(0 \leq f(x, y) \leq 255) ; \max (f(x, y))$ : o maior valor da matriz $f(x, y) ; g(x, y)$ : a matriz resultante $(0 \leq g(x, y) \leq 1)$.

Este procedimento prepara a matriz normalizada para o processo de obtenção de uma versão binária, $h(x, y)$, da imagem original, (GONZALEZ; WOODS, 2002):

$$
h(x, y)= \begin{cases}1 & \text { se } f(x, y)>L \\ 0 & \text { se } f(x, y) \leq L\end{cases}
$$

O valor do limiar $L$ é definido pelo usuário no aparelho celular em razão de possíveis diferenças na tonalidade do ágar utilizado na placa de Petri e no contraste com o tipo de microrganismo formador de colônia. O limiar a ser escolhido é aquele que identifica precisamente o início do surgimento das colônias no sistema proposto.

A quantificação de grupos de pixels brancos que representam colônias de microrganismos ocorre no bloco de medição, descrito pela equação (3):

$$
Q=\sum_{n=1}^{N} \sum_{m=1}^{M} h(n, m)
$$

sendo que $N$ e $M$ representam, respectivamente, a quantidade de linhas e colunas na imagem e $Q$ a quantidade dos pixels de interesse contidos na imagem.

Finalmente, o percentual de ocupação das colônias é determinado pela razão entre as quantidades totais de pixels brancos e de pixels pretos na imagem binária. Esta informação é exibida diretamente para o usuário na tela do aparelho celular. Neste contexto, a diferença entre as taxas de ocupação subsequentes indica a evolução espacial das colônias de microrganismos. 


\section{Resultados e discussões}

Uma imagem representativa $(2560 \times 1920$ pixels) de uma placa de Petri incubada com colônias de leveduras Saccharomyces cerevisiae é mostrada na Figura 5.

Figura 5. (a) Imagem representativa de colônias de $S$. cerevisiae incubadas em uma placa de Petri. Imagem em escala de cinza com 256 níveis. (b) Versão binária da imagem original.

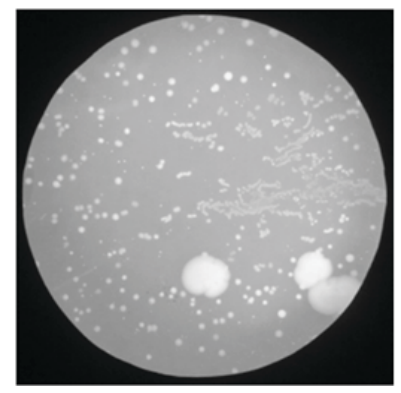

(a)

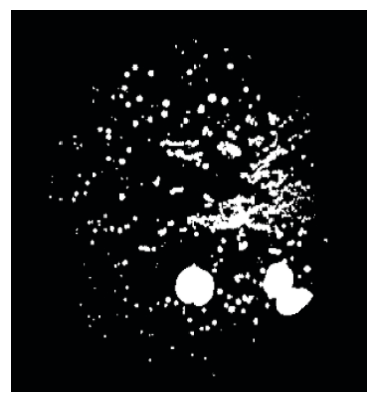

(b)
Fonte: Autor

Os ensaios experimentais determinaram a ocupação percentual de colônias em placas de Petri preparadas com ágar e incubadas com diferentes concentrações de leveduras obtidas por meio de diferentes fatores de diluições em água: $10^{-6}$, $10^{-5}, 10^{-4}, 10^{-3}$ e $10^{-2}$. O monitoramento das colônias em placa de Petri ocorreu durante um período de $38 \mathrm{~h}$ de incubação em estufa a temperatura controlada de $33,2^{\circ} \mathrm{C}$. Para cada ensaio, os dados experimentais foram determinados pela média de quatro medições.

A Figura 6 ilustra as taxas de crescimento de colônias a partir do instante que as mesmas se tornaram visíveis ao sistema óptico do aparelho celular. Para todos os fatores de diluição as medições desempenhadas pelo sistema proposto indicaram que o crescimento das colônias de leveduras cessou a partir do instante $33 \mathrm{~h}$.
Figura 6. Ocupação proporcional das colônias em cada placa de Petri determinada pelo sistema proposto sob diferentes fatores de diluição em água de soluções de $S$. cerevisiae.

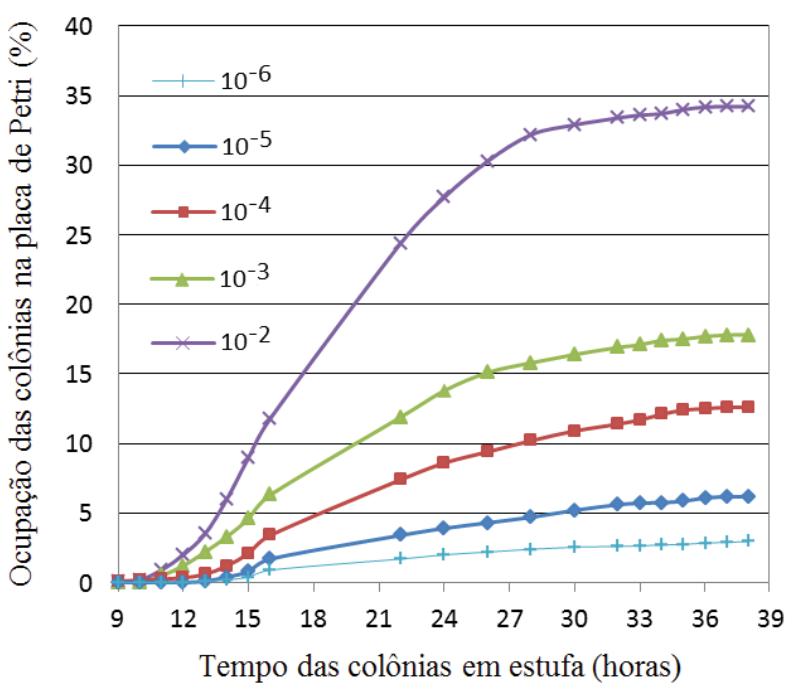

Fonte: Autor

As subsequentes comparações adotaram o fator de diluição de $10^{-4}$ pelo fato deste resultar uma melhor observação visual das colônias e também por facilitar as medições pelo método convencional. É oportuno mencionar que o método proposto é adequado para os demais fatores de diluição considerados neste trabalho, uma vez que ele não depende da quantidade e da taxa de ocupação das colônias.

As imagens capturadas pelo sistema proposto foram submetidas a um teste comparativo envolvendo processamento digital de imagem (off-line) conduzido em um computador pessoal. Para tanto, utilizou-se o software Matlab com toolbox de processamento de imagens e algoritmo de contagem de objetos. O mesmo limiar de binarização adotado no sistema proposto foi selecionado para a comparação. O resultado desta comparação é ilustrado na Figura 7. 
Figura 7. Comparação de medição entre o método proposto e o processamento de imagem em computador pessoal (MATLAB) para um fator de diluição em água de $10^{-4}$.

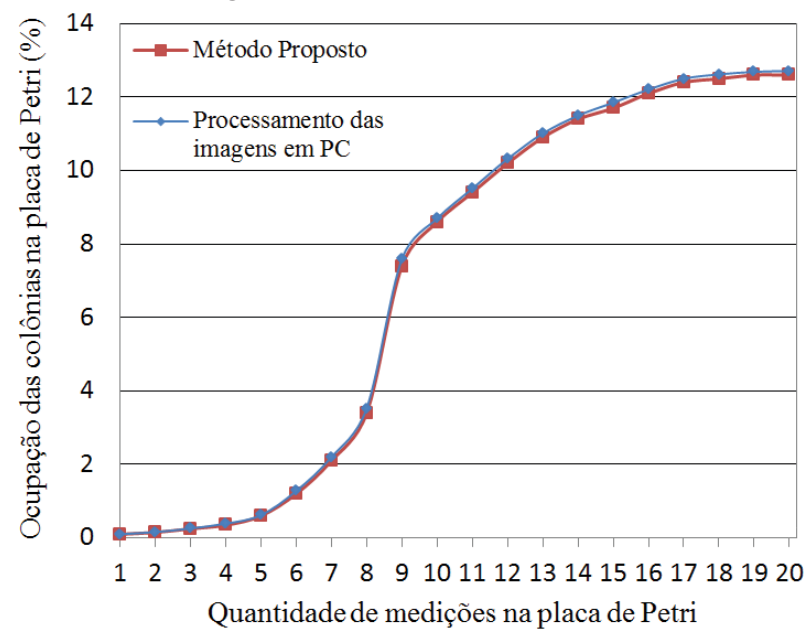

Fonte: Autor

Para propósitos práticos, as medições obtidas pelo método proposto coincidem com os valores determinados pelo algoritmo implementado em PC. Especificamente, as diferenças entre os valores de cada método estão abaixo de 0,9\%.

A partir da visualização do início do surgimento das colônias, medições convencionais foram realizadas por dois técnicos usando uma escala graduada (régua) com resolução de $0,5 \mathrm{~mm}$. A dificuldade de visualização no momento das leituras associada a essa baixa resolução contribuíram para uma baixa precisão nas medições. Para minimizar erros de leitura, cada técnico realizou duas medições com um paquímetro digital (resolução de $0,01 \mathrm{~mm}$ ) e o valor médio dessas leituras foi adotado como referência de comparação contra o método proposto. Alterações de tamanho físico dessa ordem de grandeza não são perceptíveis pela medição convencional, pois o crescimento de colônias muitas vezes não é uniforme e tampouco evoluiu de forma espacialmente organizada. Em contrapartida, o método proposto é capaz de registrar alterações morfológicas, incluindo a

excentricidade nas colônias, a qual o método de medição convencional não é capaz de detectar. Os mesmos técnicos que realizaram o monitoramento usando o método convencional utilizaram o sistema proposto nas mesmas condições e placa de Petri.

No método proposto, os 1920 pixels horizontais da câmera digital utilizada para registrar o diâmetro de $88 \mathrm{~mm}$ da placa de Petri corresponde a uma resolução óptica aproximada de $0,046 \mathrm{~mm}$.

A Figura 8 mostra as telas reais do aparelho celular do sistema proposto em um exemplo de medição.

Figura 8. Processamento de uma imagem no aparelho celular com o sistema Windows Phone: (a) Seleção do aplicativo; (b) Definição do limiar para o processamento da imagem; (c) Processamento (monitoramento) da imagem; (d) Imagem binária da placa de Petri e a ocupação percentual das colônias.

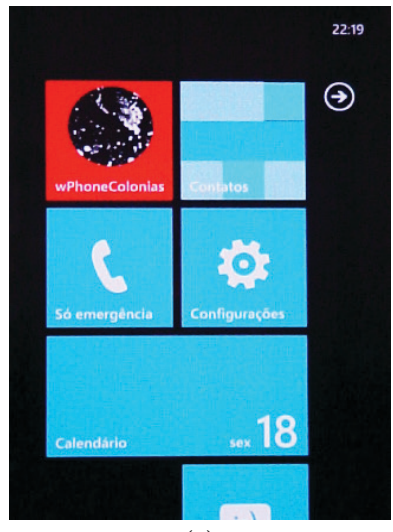

(a)

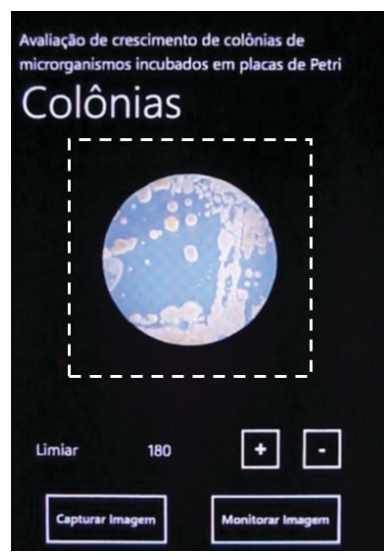

Fonte: Autor (c)

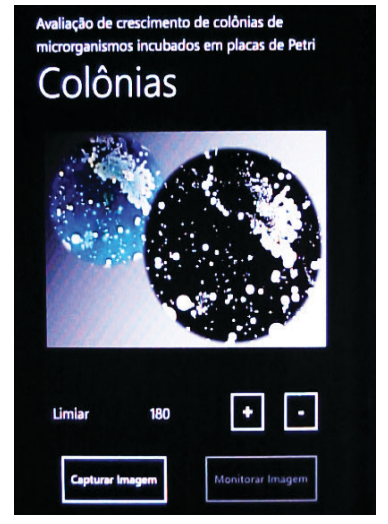

(b)

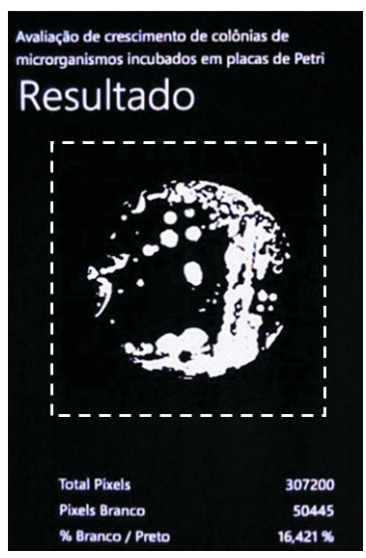

(d) 
A Figura 8(d) mostra uma imagem experimental contendo, respectivamente, 307200 e 50445 pixels pretos e brancos. Estes valores correspondem a uma ocupação de $16,42 \%$ pelas colônias, i.e. pixels brancos. Se a área sob análise fosse unicamente delimitada pela borda circular do disco de Petri, uma inspeção visual na Figura 8(c) poderia indicar um índice de ocupação muito superior ao valor calculado. No entanto, verificou-se que os pixels pretos localizados na região definida pelo exterior do perímetro circular do disco de Petri e o interior do retângulo tracejado da Figura 8(c), por exemplo, correspondem ao interior do tubo de proteção posicionado entre a câmera fotográfica e o disco de Petri (Figura 3b). Neste contexto, a superior quantidade de pixels pretos em uma ordem de magnitude contribuiu para a reduzida estimativa da taxa de ocupação das colônias. Embora seja difícil estabelecer uma correlação direta entre a estimativa numérica e a informação visual da Figura 8(c), por exemplo, a medida da taxa de evolução dos microrganismos, determinada pela diferença entre imagens subsequentes, não é afetada pelo registro dos pixels pretos produzidos pelo tubo de proteção.

Uma análise comparativa entre os diferentes métodos de medição adotados neste trabalho é ilustrada na Figura 9. A mesma placa de Petri foi selecionada em todas as medições, independente do método de medição. Na comparação de medição os valores obtidos pelo método proposto foram coletados, processados e exibidos ao usuário diretamente na tela do aparelho celular.

Devido às diferenças significativas entre as medições pela escala graduada, os valores médios das medições obtidas com o paquímetro digital foram adotados como referência no método convencional.

No total, o procedimento experimental observou 37 colônias de leveduras durante todo o período de incubação.

Para cada ponto experimental foram realizadas quatro medições, tanto para o método proposto 42 paquímetro digital. Ao longo do intervalo de observação foi possível detectar diferenças percentuais significativas nas dimensões físicas das colônias. Diferente da técnica convencional, a qual demanda anotações manuais dos respectivos valores e cálculos extras, o método proposto apresentou a taxa de ocupação das colônias à medida que as imagens eram capturadas. Variações (erros de repetibilidade) de medição foram de $14 \%$ a $33 \%$ para a régua, de $3,7 \%$ a $5,9 \%$ para o paquímetro (Figura 9) e $0,16 \%$ a $0,23 \%$ para o método proposto (Figura 10). A resolução de 0,5 $\mathrm{mm}$ da escala graduada, associada à dificuldade de visualização, contribuiu para produzir medidas com maiores erros. O paquímetro digital, por sua vez, apresentou leituras diretamente no mostrador do instrumento, com a desvantagem da necessidade de realizar o posicionamento manual sobre a placa de Petri. Outro inconveniente do método manual é o tempo demandado nas sucessivas identificações das colônias previamente monitoradas sobre a região externa da placa de Petri, necessárias para evitar repetições desnecessárias de medidas.

Para manter a identificação regular dos pixels durante os testes comparativos, a aquisição das imagens no sistema proposto foi conduzida à mesma distância focal de $150 \mathrm{~mm}$. O alinhamento entre a placa de Petri em relação à câmera do aparelho celular também foi mantido inalterado.

Figura 9. Comparação entre o método proposto, método convencional com uma escala graduada e paquímetro digital para um fator de diluição igual a $10^{-4}$.

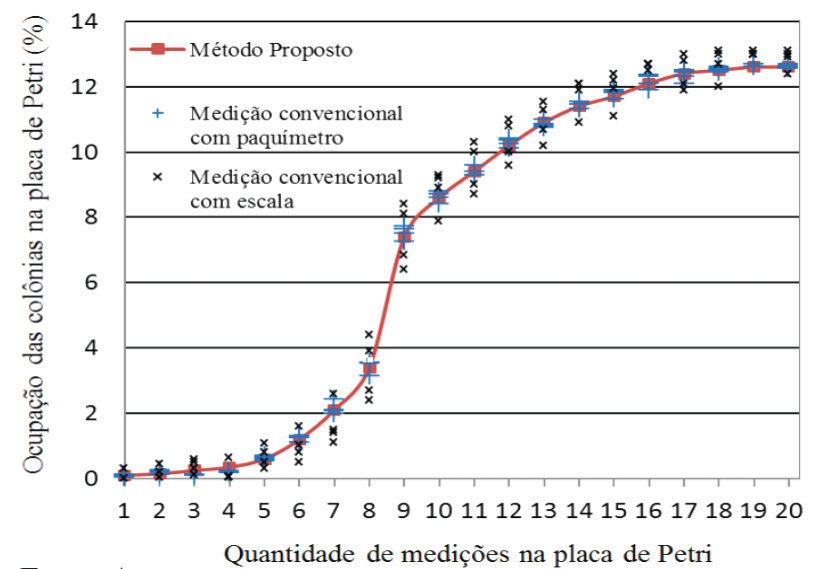

Fonte: Autor 
Figura 10. Comparação do erro de repetibilidade entre as medições pelos métodos proposto e convencional em colônias de Saccharomyces cerevisiae.

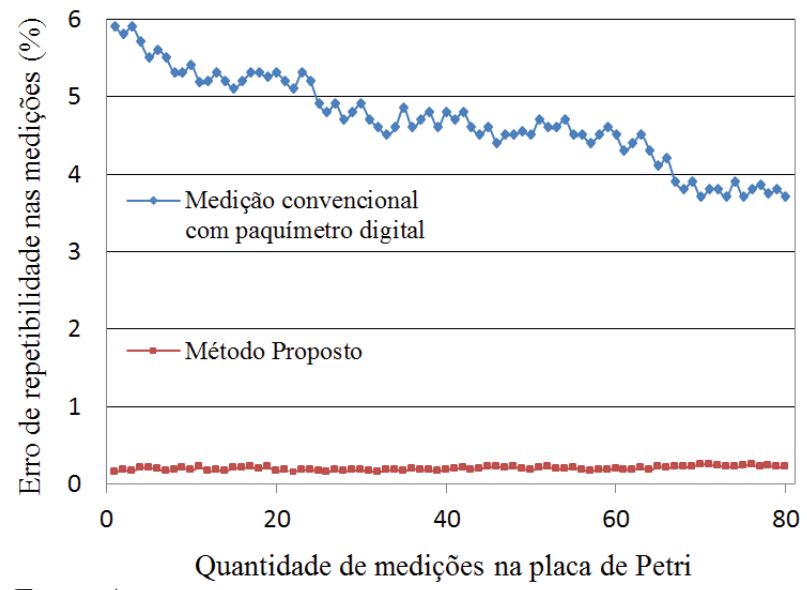

Fonte: Autor

A comparação na Figura 10 mostra que o erro de repetibilidade para o paquímetro digital superou aquele do da medição automática, independente da quantidade de medições realizadas. Em particular, esses erros foram maiores próximos à fase exponencial de crescimento das colônias, na qual as dimensões medidas das colônias se aproximam da resolução do paquímetro digital. Em contrapartida, o erro produzido pelo método proposto se manteve baixo e praticamente constante para baixas e altas quantidades de pixels que representam as fases de crescimento das colônias.

Uma avaliação do desempenho do método proposto (Figura 11) demonstra que foram necessários $9 \mathrm{~s}$ para capturar e processar uma imagem contendo 37 colônias incubadas em uma placa de Petri, contra uma média de 271 s para o método convencional (paquímetro digital). Essas durações correspondem a 80 medições coletadas sob a mesma placa de Petri. Observa-se que o tempo demandado pelo método manual é diretamente proporcional à quantidade de colônias sob investigação. Embora o aumento da área de colônias na placa de Petri seja considerado um fator de desempenho num contexto de avaliação do comportamento de microrganismos, a quantidade de colônias foi aqui utilizada apenas para os propósitos de comparação de rapidez entre os métodos avaliados.

Figura 11. Comparação do tempo de medição pelos métodos proposto e convencional (paquímetro digital).

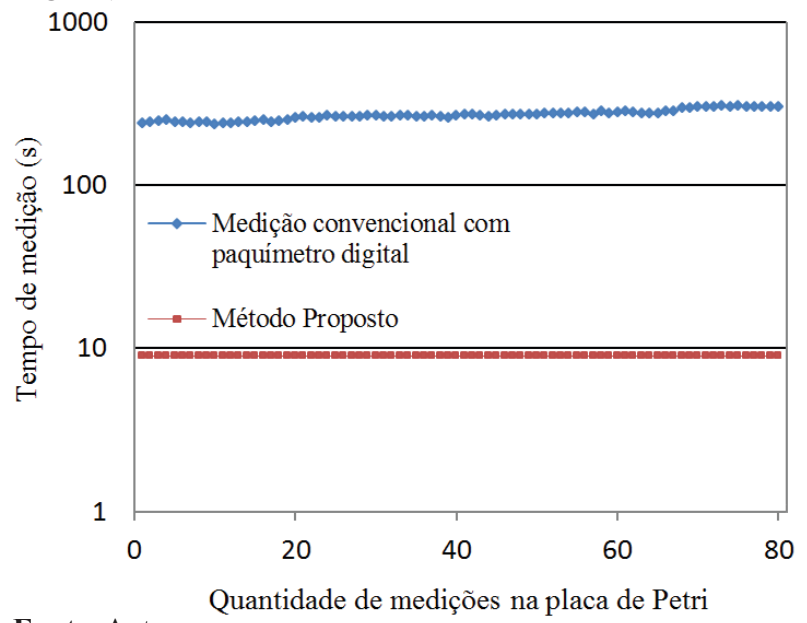

Fonte: Autor

O uso de um paquímetro digital demandou mais tempo na obtenção da medição devido à necessidade de se realizar duas medições sucessivas e posterior registro dos valores e cálculos manuais. Cada técnico realizou duas medições para cada colônia para obter a correspondente média de referência para cada fase de evolução das colônias.

A comparação de erro de repetibilidade em relação ao tamanho das colônias observadas é ilustrada na Figura 12. Nota-se que os erros apresentados pelo paquímetro digital superam aqueles obtidos pelo método proposto e são maiores para menores tamanhos físicos de colônias. 
Figura 12. Comparação de erro de repetibilidade entre os métodos proposto e convencional (paquímetro digital) em relação às dimensões físicas das colônias.

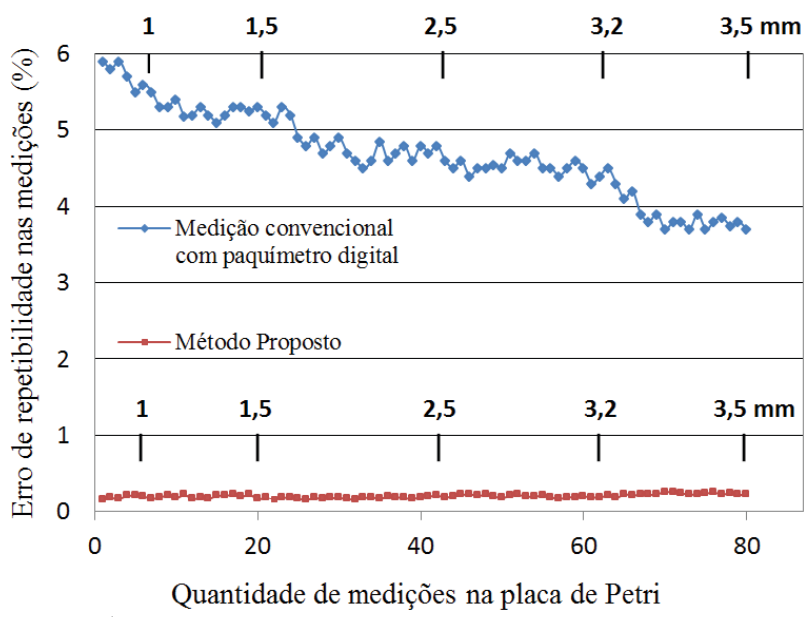

Fonte: Autor

Quantidade de medições na placa de Petri

Os resultados da Figura 12 indicam que, à medida que as colônias aumentaram em até 3,5 $\mathrm{mm}$ em tamanho físico, menores são os erros registrados pelo método de medição convencional. Este comportamento ocorreu em razão da maior facilidade na visualização das colônias ao longo da sua curva de crescimento. Para esses casos, o erro de repetibilidade das medições pelo método manual reduziu de 5,9\% para $3,7 \%$ entre a $1^{\text {a }}$ e a $80^{\mathrm{a}}$ medição. Em contrapartida, o erro de repetibilidade exibido pelo método proposto sofreu pequenas variações, atingindo uma imprecisão máxima de $0,23 \%$.

\section{Conclusão}

Os resultados experimentais preliminares aqui apresentados demonstraram que um método baseado em análise de imagem para o monitoramento da taxa de crescimento de colônias de leveduras superou a técnica convencional sob diversos aspectos práticos.

A plataforma móvel produziu resultados mais exatos e consistentes num menor tempo de medição, independente da quantidade e do tamanho físico das colônias sob observação.

Além disso, o uso de uma plataforma móvel com a base suporte portátil (leve e pequena) oferece a vantagem adicional da mobilidade, especialmente interessante quando diferentes análises devem ser conduzidas em diferentes ambientes. Adicionalmente, a medida da taxa de ocupação das colônias é exibida diretamente na tela do equipamento móvel à medida que as imagens são capturadas e processadas, diferentemente do método convencional que demanda anotações e cálculos manuais para a obtenção de estimativas de menor significância estatística.

Em relação à análise de imagens utilizando computador pessoal e software Matlab, a proposta automática de (MEMARIAN et al., 2007) identificou o crescimento de colônias de $S$. cerevisiae 64 vezes mais rápido que o seu método convencional. $\mathrm{O}$ método proposto no presente trabalho demonstrou ser no mínimo 27 vezes mais rápido que o método de medição manual considerado, sem a exigência de experiência em metrologia dimensional. De fato, os técnicos que conduziram as medições experimentais receberam apenas orientações sobre o manuseio do sistema de aquisição de imagem e o uso do aplicativo no aparelho celular.

Em melhorias futuras pretende-se desenvolver um banco de dados para o sistema proposto composto por diferentes limiares de segmentação. Neste contexto, o usuário poderá escolher um valor definido previamente, de acordo com o microrganismo e o substrato na placa de Petri.

\section{Referências}

ADDINALL, S. G.; DOWNEY, M.; YU, M.; ZUBKO, M. K.; DEWAR, J.; LEAKE A.; HALLINAN, J.; SHAW, O.; JAMES, K.; WILKINSON, D. J.; WIPAT, A.; DUROCHER, D.; LYDALL, D. A genomewide suppressor and enhancer analysis of cdc13-1 reveals varied cellular processes influencing telomere capping in Saccharomyces cerevisiae. Genetics, v. 180, p. 2251-2266, 2008. 
BARAZZETTI, L.; SCAIONI, M. Crack measurement: Development, testing and applications of an automatic image-based algorithm. ISPRS Journal of Photogrammetry and Remote Sensing, v. 64, p. 285-296, 2009.

BISTON, M. C.; CORDE, S.; CAMUS, E.; MARTI-BATTLE, R; ESTEVE, F.; BALOSSO, J. An objective method to measure cell survival by computer-assisted image processing of numeric images of Petri dishes. Physics in Medicine and Biology, v. 48, p. 1551-1563, 2003.

BOTTIGLI, U.; CARPINELLI, M.; FIORI, P. L.; GOLOSIO, B.; MARRAS, A.; MASALA, G. L.; OLIVA, P. A. New automatic system of cell colony counting. World Academy of Science, Engineering and Technology, v.15, p. 159-163, 2006.

CARPENTER, A. E.; JONES T. R.; LAMPRECHT, M.R.; CLARKE, C.; HANG, I. H.; FRIMAN O.; GUERTIN, D. A.; CHANG, J. H.; LINDQUIST, R. A.; MOFFAT, J.; GOLLAND, P.; SABATINI, D. M. CellProfiler: image analysis software for identifying and quantifying cell phenotypes. Genome Biology, v. 7, n. 10, p. 1-10, 2006.

CHEN, W. B; ZHANG, C. An automated bacterial colony counting and classification system. Information Systems Frontiers, v. 11, n. 4, p. 349368, 2009.

COSTELLO, P. J.; MONK, P. R. Image analysis method for the rapid counting of Saccharomyces cerevisiae cells. Applied Environmental and Microbiology, v. 49, n. 4, p. 863-866, 1985.

GHAEMMAGHAMI, S.; HUH, W. K.; BOWER, K.; HOWSON, R. W.; BELLE A.; DEPHOURE N.; O'SHEA E. K.; WEISSAMAN, J. S. Global analysis of protein expression in yeast. Nature, v. 425, p. 737-774, 2003.

GOFFEAU, A.; BARRELL B. G.; BUSSEY, H.; DAVIS R. W.; DUJON, B.; FELDMANN, H.; GALIBERT, F.; HOHEISEL, J. D.; JACQ, C.; JOHNSTON, M. Life with 6000 genes. Science, v. 274, p. 563-547, 1996.

GONZALEZ, R. C.; WOODS, R. Digital image processing. 2. ed. New Jersey: Prentice Hall, 2002.
KROGAN, N. J.; CAGNEY, G.; YU, H.; ZHONG, G.; GUO, X.; IGNATCHENKO, A.; LI, J.; PU, S.; DATTA, N.; TIKUISIS, A. P.; PUNNA, T.; PEREGRIN, A. J. M.; SHALES, M.; ZHANG, X.; DAVEY, M.; ROBINSON, M.. D; PACCANARO, A.; BRAY, J. E.; SHEUNG, A.; BEATTIE, B.; RICHARDS, D. P.; CANADIEN, V.; LALEV, A.; MENA, F.; WONG, P.; STAROSTINE, A.; CANETE, M. M.; VLASBLOM, J.; WU, S.; ORSI, C.; COLLINS, S. R.; CHANDRAN, S.; HAW, R.; RILSTONE, J. J.; GANDI, K.; THOMPSON, N. J.; MUSSO, G.; ST ONGE, P.; GHANNY, S.; LAM, M. H.; BUTLAND, G.; ALTAF-UI, A. M.; KANAYA, S.; SHILATIFARD, A. O'SHEA, E.; WEISSMAN, J.S.; INGLES, C. J.; HUGHES, T. R.; PARKINSON, J.; GERSTEIN, M.; WODAK, S. J.; EMILI, A.; GREENBLATT, J. F. Global landscape of protein complexes in the yeast Saccharomyces cerevisiae. Nature, v. 440, p. 637-643, 2006.

LAWLESS, C.; WILKINSON, D. J.; YOUNG, A.; ADDINALL, S. G.; LYDAL, D. A. Colonyzer: automated quantification of micro-organism growth characteristics on solid agar. BMC Bioinformatics, v. 11, p. 287-299, 2010.

LI, Y.; WADSO, L. Simultaneous measurements of colony size and heat production rate of a mould (Penicilliumbrevicompactum) growing on agar. Journal Therm Anal Calorim, v. 104, p. 105-111, 2011.

LONDON, R.; SCHWEDOCK, J.; SAGE, A.; VALLEY, H.; MEADOWS, J.; WADDINGTON, M.; STRAUS, D. An automated system for rapid non-destructive enumeration of growing microbes. Plos One, v. 5, n. 1, e8609, 2010.

MEMARIAN, N.; JESSULAT, M.; ALIREZAIE, J.; MIR-RASHED, N.; XU, J.; ZAREIE, M.; SMITH, M.; GOLSHANI, A. Colony size measurement of the yeast gene deletion strains for functional genomics. BMC Bioinformatics, v. 8, n. 117, Apr 2007.

ROBINSON, A.; SADR-KAZEMI, N.; DICKASON, G.; HARRISON, S. T. L. Morphological characterization of yeast colony growth on solid media using image processing. Biotechnology Techniques, v. 12, n. 10, p. 763-767, 1998. 
SASANO, Y.; WATANABE, D.; UKIBE, K.; INAI, T.; OHTSU, I.;SHIMOI, H.; TAKAGI, H. Overexpression of the yeast transcription activator Msn2 confers furfural resistance and increases the initial fermentation rate in ethanol production. Journal of Bioscience and Bioengineering, v.113, n. 4, p. 451-455, 2012.

YAMASHITA, Y.; KUWASHIMAM M.; NONAKAM T.; SUZUKI, M. On-line measurement of cell size distribution and concentration of yeast by image processing. Journal of Chemical Engineering of Japan, v. 26, n. 6, p. 615-619, 1993.

ZALEWSKI, K.; BUCHHOLZ, R. Morphological, analysis of yeast cells using an automated image processing system. Journal of Biotechnology, v. 48, p. 43-49, 1996. 